\title{
Two Cases of Acute Epidural Hematoma Formation after Cervical InTERLAMINAR EPIDURAL STEROID INJECTIONS
}

\author{
John R. Swicegood, MD¹, Laxmaiah Manchikanti, MD², Ramsin M. Benyamin, MD ${ }^{3}$, and \\ Joshua A. Hirsch, MD ${ }^{4}$
}

Cervical interlaminar epidural injections are rarely associated with epidural hematoma resulting in surgical decompression. Multiple strategies in the prevention of epidural hematoma after cervical epidural injections are based on cessation of therapy in patients with bleeding disorders on antiplatelet therapy, fish oil, and multiple other drugs. Multiple guidelines from organizations across the globe have recommended continuation of nonsteroidal anti-inflammatory drugs (NSAIDs) and low dose aspirin. Guidelines also have recommended to continue or cessation of antithrombotic agent therapy based on risk benefit ratio, due to associated risks of thrombotic events with interventional techniques or other surgeries with discontinuation of antiplatelet therapy.

We report 2 cases of cervical epidural hematoma requiring surgical decompression, without residual dysfunction.

The first case was in a 41-year-old Caucasian woman with controlled hypertension; however, with no drug therapy contributing to bleeding and 2 uneventful cervical interlaminar epidural injections, the patient developed a cervical epidural hematoma after the third procedure which was performed uneventfully. She developed rapid paralysis and underwent surgical decompression without residual dysfunction.

The second case involved a cervical epidural injection resulting in a cervical epidural hematoma. This patient was on $81 \mathrm{mg}$ of aspirin and was continued with therapy. Surgical decompression was carried out with no residual dysfunction. This patient also received Toradol for pain control in the recovery room which may have exacerbated the epidural hematoma.

These 2 case reports illustrate that cervical epidural hematoma is a rare, but fatal occurrence associated with cervical epidural injections. Appropriate patient selection with constant vigilance on post operative course and follow-up treatment with surgical intervention or conservative management is crucial. It is also crucial to understand the role of loss of resistance technique with air only which may complicate the closed space phenomenon of cord compression and post procedure pain at the injection site which is different from the pain ever experienced by the patient with the previous injections.

Key words: Interventional techniques, cervical epidural injections, cervical epidural hematoma, bleeding disorders, aspirin, antithrombotic agents, Ketoralac
From : ${ }^{1}$ Advanced Interventional Pain and Diagnostics of Western Arkansas, Fort Smith, AR; ${ }^{2}$ Pain Management Center of Paducah, Paducah, $\mathrm{KY}$, and University of Louisville, Louisville, KY; ${ }^{3}$ Millennium Pain Center, Bloomington, IL, and University of Illinois, Urbana-Champaign, IL; and ${ }^{4}$ Massachusetts General Hospital and Harvard Medical School, Boston, MA

Author for correspondence: Laxmaiah Manchikanti, M.D.

Address: Pain Management Center of Paducah, 2831 Lone Oak Rd, Paducah, Kentucky 42003

E-mail: drlm@thepainmd.com
Hematoma following epidural injections is expected in patients prescribed antithrombotic medications or over-the-counter antithrombotic medications to reduce thromboembolic events. While the discussion continues in reference to the cessation of antithrombotic therapy in patients with known risk factors, multiple case reports have been presented in patients without antithrombotic therapy or in those patients with low dose aspirin therapy with or without nonsteroidal anti-inflammatory agents. Multiple guidelines 
across the globe have uniformly recommended the continuation of low dose aspirin and nonsteroidal anti-inflammatory drugs (NSAIDs) (1-7). The potential contribution of fish oil (6), fluoxetine, and Ketoralac (7) have been described. The extensive review of the literature indicates that the risks of discontinuing anticoagulant therapy may be greater than continuation of the therapy $(1-4,8,9)$. Manchikanti et al, in a prospective evaluation of bleeding risks of interventional techniques in chronic pain $(2,10)$, over a period of 20 months with involvement of 2,376 cervical interlaminar epidural injections, have reported no incidence of epidural hematoma. Manchikanti et al (11) have also described subarachnoid punctures in the cervical spine in 61 cases with no evidence of epidural hematoma formation. In a case report and literature review Manchikanti et al (4) have reported 2 cases of epidural hematoma, one requiring a surgical decompression and other one managed conservatively with a extremely low prevalence of 2 cases over a period of 16 years or $0.0085 \%$ in a large tertiary referral center performing 23,523 cervical epidural injections from 2000 through 2015. In another manuscript assessing interventional pain management practices and patterns of perioperative management of antiplatelet and anticoagulant therapy, serious complications of thrombotic events were 3 times more frequent than bleeding complications with 162 thrombotic events and 55 serious bleeding complications from epidural hematomas (8). Interestingly, this assessment also showed similar bleeding complications with epidural hematomas whether antiplatelet therapy was continued or discontinued with 26 hematomas in patients without cessation of therapy and 29 with cessation of therapy. The major disadvantage of the interpretation of this report is that the exact proportion of patients with or without cessation is not known. In a recent report Endres et al (9) showed that anticoagulants were continued in 4,766 procedures without cessation of therapy and 2,296 procedures with cessation of the therapy. They reported serious morbidity including 2 deaths in 9 patients after cessation of therapy. Further, there have been multiple other case reports of epidural or subdural hematoma following cervical epidural injections (4-7,12-17); however, the reports of spontaneous epidural hematoma are abundant (1).

We report 2 cases of cervical epidural hematoma in patients with no antithrombotic therapy, performed in a tertiary referral center that has frequently performed cervical epidural injections since 1993.

\section{CASE REPORTS}

The first case involves a healthy 41-year-old Caucasian woman with controlled hypertension without antithrombotic therapy. In May 2010 she was referred for evaluation and treatment of chronic neck and upper extremity pain. Her baseline magnetic resonance imaging (MRI) showed spondylotic ridging at C4-5, C5-6, and C6-7 with left paracentral disc protrusion at C4-5, a right paracentral disc protrusion at C5-6, and a broad based disc bulging at C6-7. She underwent 2 cervical interlaminar epidural injections uneventfully. The third procedure was performed at the C7-T1 interspace, with injection of $2 \mathrm{~mL}$ of contrast $1 \mathrm{~mL}$ of $1 \%$ lidocaine mixed with $12 \mathrm{mg}$ of betamethasone. Using the loss of resistance technique a single attempt was performed without any bleeding pattern, etc. She reported that the injection felt somewhat different and she felt a pop. The procedure was performed without sedation in a sterile setting. She walked in the recovery room and was discharged in satisfactory condition. She called one hour later stating that she was paralyzed. She was seen in the emergency room and was admitted. She was initially managed with conservative management since there was no neurosurgeon available. Subsequently, she was transferred to another hospital where she underwent surgical decompression without residual dysfunction. MRI prior to surgical intervention showed a dorsal epidural hematoma in the cervical and thoracic spine, worse at C7-T2, as shown in Fig. 1. There was compression of the cord at T1-2 as shown in Fig. 2. MRI showed that at level T4, the dorsal epidural hematoma measured $3.3 \mathrm{~mm}$ in thickness and this gradually tapered to essentially nothing at the level of T8.

The second case involves a 76-year-old Caucasian man, in December 2013, with chronic neck and upper extremity pain. Patient was diabetic and was receiving low dose aspirin $81 \mathrm{mg}$ and vitamin D3. Patient's MRI showed disc protrusion at C5-6 with mild canal stenosis and mild left foraminal narrowing. There was also spondylotic ridging with superimposed disc protrusion at C6-7 with more moderate canal stenosis and bilateral foraminal narrowing, left greater than right. The 
patient underwent an uneventful repeat cervical epidural injection at C7-T1. Using the loss of resistance technique, $1 \mathrm{~mL}$ contrast $1 \mathrm{~mL}$ of $1 \%$ lidocaine mixed with $12 \mathrm{mg}$ of betamethasone and $4 \mathrm{mg}$ of dexamethasone were injected uneventfully. He started developing excruciating pain in the recovery room. At this time, he was administered with $30 \mathrm{mg}$ of intravenous Ketoralac (Toradolß); however, this did not change his pain significantly. No neurologic symptoms were observed and he was functioning normally except for the residual paralysis from his previous cerebrovascular accident (CVA). Considering potential of an epidural hematoma, over the course of next 30 minutes, he was taken to the local hospital and underwent computed tomograph (CT) scan of the cervical and thoracic spine which revealed a small amount of air and contrast and a small amount of blood which was diffused without loculation as shown in Figs. 3 and 4. There were no neurological symptoms 3 hours after the epidural injection. Since there was no neurosurgeon on call available, the patient was transferred to a different hospital. Subsequently, the patient underwent decompression and did well without any residual dysfunction.

\section{DISCUSSION}

We report 2 cases of cervical epidural hematoma, with one patient not on any type of antithrombotic therapy and one patient receiving low dose aspirin therapy, who also received Toradol in the recovery room. Both patients were diagnosed rapidly and underwent appropriate surgical decompression. Both recovered without residual dysfunction.

Despite multiple case reports of cervical epidural hematomas over the years (4-12), they

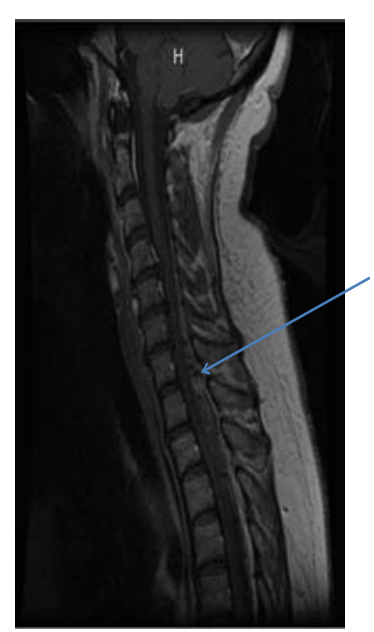

1B. Sag post-contrast $\mathrm{T} 1$ weighted images of the cervical spine demonstrating epidural hematoma. Dark spots likely represents air in the hematoma.
2A. MRI of thoracic spine sagittal T2WI demonstrating lower limit of epidural hematoma.

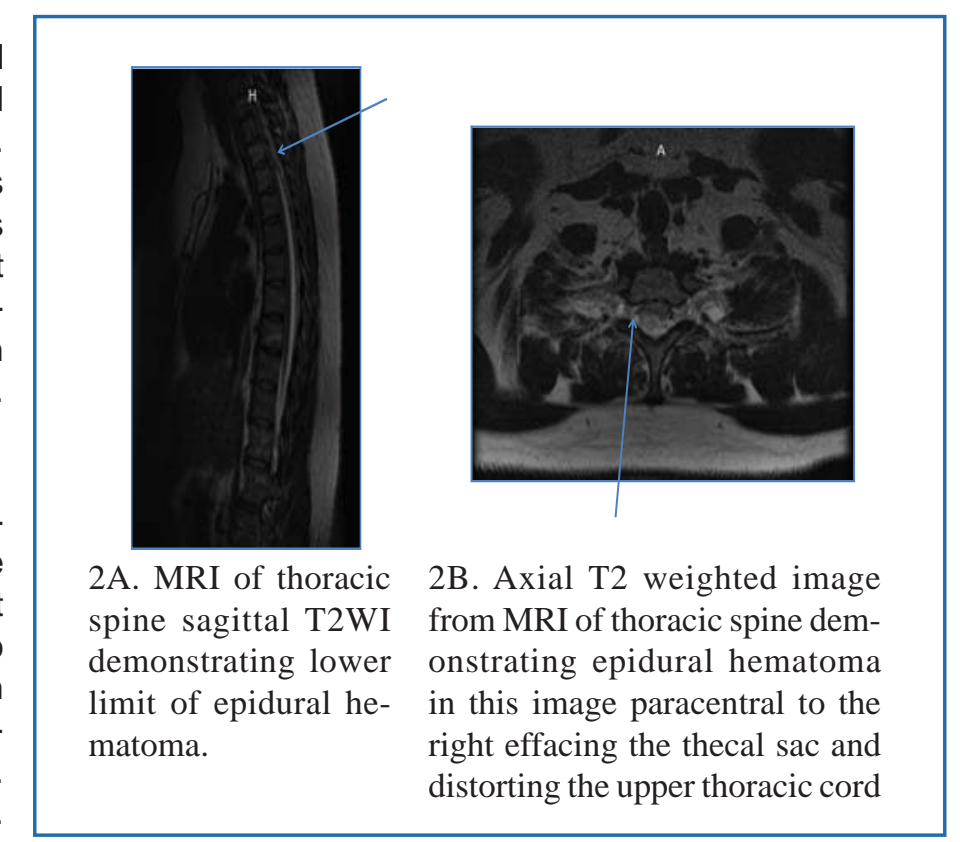

Fig. 2. Cervical epidural hematoma: sagittal and axial views showing lower limits into thoracic spine. 


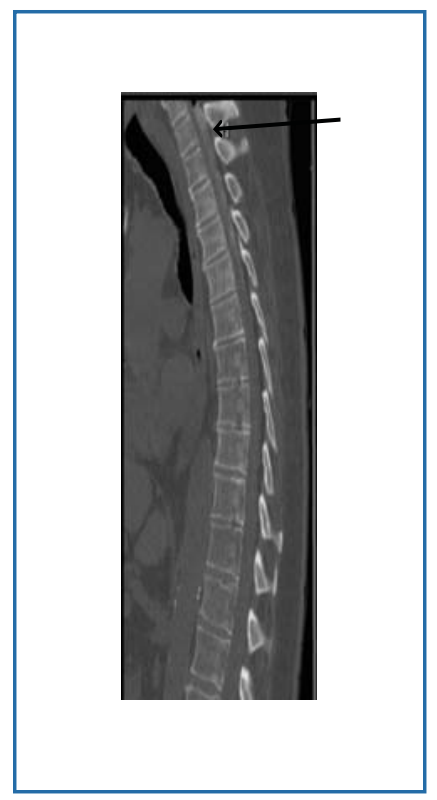

Fig. 3. Sagittal reconstruction demonstrating epidural hematoma on CT scan: arrow indicates epidural hematoma. with 4 additional cases in the thoracic and lumbar spine. Fitzgibbon (16), in a report for the American Society of Anesthesiologist (ASA) closed claims project, reported 6 claims after assessing paraplegia or quadriplegia due to epidural hematoma resulting from an interventional pain management procedure during the period between 1970 and 2000. Rathmell et al (17), also describing injury and liability associated with cervical procedures for chronic pain from 2005 to 2008, reported 3 cases of compressive epidural hematoma secondary to cervical epidural injections. Consequently, the literature contains no prevalence statistics for cervical epidural hematoma related to epidural injections. Multiple reasons for this have been described including under reporting as a major cause.

In addition to antithrombotic therapy, multiple other mechanisms have been implicated in the formation of epidural hematoma, specifically after needle placement with epidural injections. These mechanisms point towards anatomic abnormalities of the vertebral column with epidural venous and arterial malformations $(1,7,18-20)$. To support these theories, 3 cases of post operative epidural hematoma as a complication of anterior cervical discectomy have been described (21). Other risks include anatomic abnormalities of the vertebral column leading to technical difficulties or repeat punctures, older age, intrinsic thrombocytopenia, or platelet dysfunction, renal failure, and other related coagulopathies including hemophilia (16-18,20,22-28). Despite all the mechanisms and theories, antithrombotic or anticoagulant therapy has been described as the main culprit. As described overwhelmingly in the literature $(1,2,8,9)$, the risk of thrombotic events may be higher

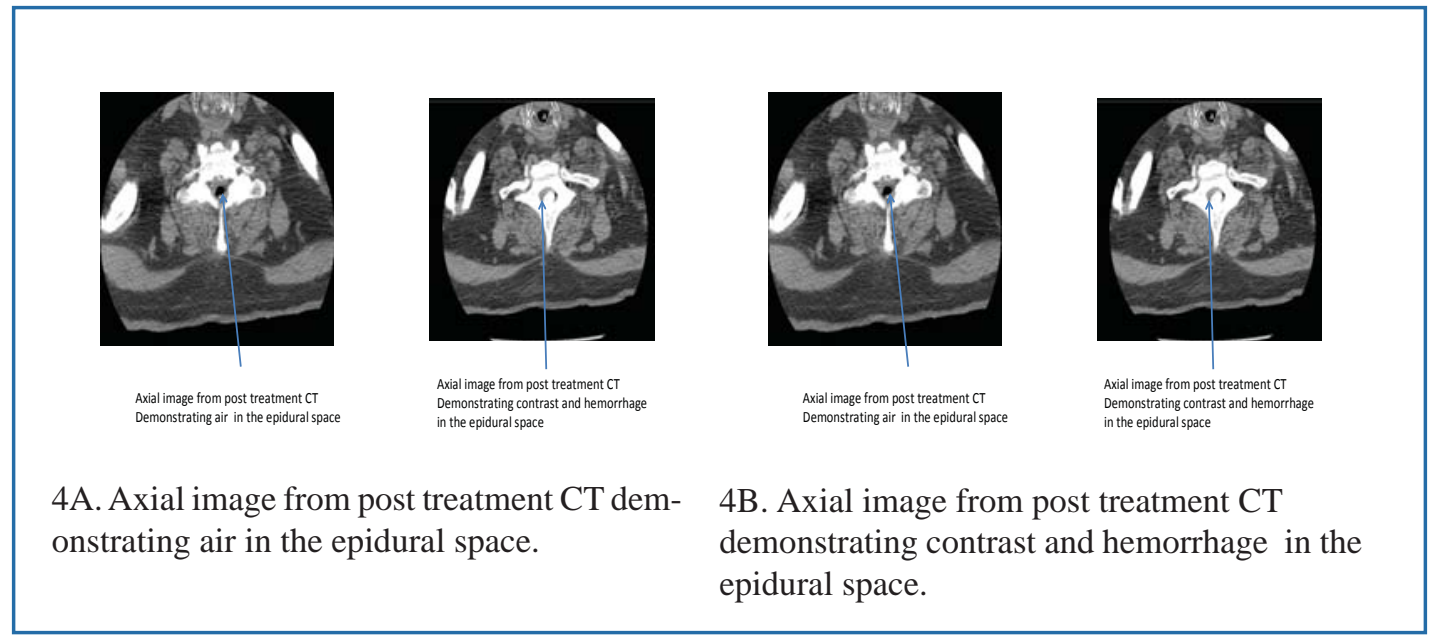

Fig. 4. Axial images of epidural hematoma. 
Acute Epidural Hematoma after Cervical Epidural Injection

with cessation of antithrombotic therapy. Multiple instances of cerebral or cardiovascular thrombotic events have been reported in the past with residual complications $(1,2,4,8,9)$. Thus far, 2 prospective evaluations have provided evidence for the lack of increased risks associated with continuation of antithrombotic therapy. In these 2 case reports, we have presented one case with no antithrombotic therapy and the second case with low dose aspirin of $81 \mathrm{mg}$ which has been recommended not to be discontinued by all authorities. However, in the second case, the patient was also administered with Ketoralac $30 \mathrm{mg}$. Ketoralac has been reported to be associated with increased incidence of cervical epidural hematoma (7). Recent descriptions of safeguards do not seem to prevent or protect against dural punctures or epidural hematoma formation (29-31). Further, the literature has reported a higher prevalence of epidural hematoma formation with continuous epidurals compared to single epidural injections $(26,32,33)$. Kreppel et al (26) reported that $30 \%$ of the cases in the literature were due to idiopathic or spontaneous origin, $17 \%$ were related to anticoagulation, and only $10 \%$ were related to spinal or epidural anesthesia. In addition, the literature also shows that the majority of the cases were related to anticoagulated patients or patients with thrombocytopenic disorders (32-34) undergoing continuous epidural anesthesia administration with catheter placement. The previous literature shows that there have been at least 3 cases related to aspirin or other NSAIDs to which this case reports ads as a fourth case (4). There also have been 2 cases related to low molecular weight heparin and 2 cases related to fibrinolytic therapy. However, none of these

\section{REFERENCES}

1. Manchikanti L, Falco FJE, Benyamin RM, Caraway DL, Kaye AD, Helm II S, Wargo BW, Hansen H, Parr AT, Singh V, Swicegood JR, Smith HS, Schultz DM, Malla Y, Hirsch JA. Assessment of bleeding risk of interventional techniques: A best evidence synthesis of practice patterns and perioperative management of anticoagulant and antithrombotic therapy. Pain Physician 2013; 16:SE261-SE318.

2. Manchikanti L, Malla $\mathrm{Y}$, Wargo BW, Cash KA, McManus $C D$, Damron KS, Jackson SD, Pampati V, Fellows B. A prospective evaluation of bleeding risk of interventional techniques in chronic pain. Pain Physician 2011; 14:317-329.

3. Manchikanti L, Hirsch JA. Neurological complications associated with epidural steroid injections. Curr Pain Headache Rep cases were cervical epidural injections except the case in this report.

Two important factors in managing epidural hematoma appear to be severe and unusual pain at the site of injection and loss of resistance technique with air which may lead to cord compression with complication of closed space phenomena.

\section{CONCLUSION}

In conclusion, we report 2 cases of cervical epidural hematoma formation after cervical epidural injection for chronic cervical disorders in one patient without any sort of antithrombotic therapy and in a second patient receiving low dose aspirin therapy complicated by administration of Ketorolac. The important aspects in rapid diagnosis are related to post procedure axial pain at the injection site different from previous pain experienced with or without previous injections. Loss of resistance with air may also complicate the closed space phenomenon of cord compression. Intravenous steroid administration as soon as the diagnosis is made may assist in delaying the neurological damage. However, vigilance and surgical intervention resulted in appropriate outcomes without residual complications.

\section{ACKNOWLEDGMENTS}

The authors wish to thank Laurie Swick, BS, for manuscript review, and Tonie M. Hatton and Diane E. Neihoff, transcriptionists, for their assistance in preparation of this manuscript. We would like to thank the editorial board of Pain Physician for review and criticism in improving the manuscript.

2015; $19: 482$.

4. Manchikanti L, Malla Y, Benyamin RM, Hirsch JA. Prevalence of epidural hematoma following cervical epidural injections in interventional pain management settings: Literature review with two case reports. IPM Reports 2017; 1:11-17.

5. Benyamin RM, Vallejo R, Wang V, Kumar N, Cedeño DL, Tamrazi A. Acute epidural hematoma formation in cervical spine after interlaminar epidural steroid injection despite discontinuation of clopidogrel. Reg Anesth Pain Med 2016; 41:398-401.

6. Jenkie EJ, Benyamin RM, Manchikanti L. Fish oil as a potential contributor to epidural hematoma following cervical epidural steroid injection: A case report and focused literature review. IPM Reports 2017; 1:19-26. 
7. Chien GC, McCormick Z, Araujo M, Candido KD. The potential contributing effect of ketorolac and fluoxetine to a spinal epidural hematoma following a cervical interlaminar epidural steroid injection: A case report and narrative review. Pain Physician 2014; 17:E385-E395

8. Manchikanti L, Benyamin RM, Swicegood JR, Falco FJE, Datta S, Pampati V, Fellows B, Hirsch JA. Assessment of practice patterns of perioperative management of antiplatelet and anticoagulant therapy in interventional pain management. Pain Physician 2012; 15:E955-E968.

9. Endres S, Shufelt A, Bogduk N. The risks of continuing or discontinuing anticoagulants for patients undergoing common interventional pain procedures. Pain Med 2016 Jun 12. [Epub ahead of print].

10. Manchikanti L, Malla Y, Wargo BW, Cash KA, Pampati V, Fellows B. A prospective evaluation of complications of $10,000 \mathrm{flu}-$ oroscopically directed epidural injections. Pain Physician 2012; 15:131-140.

11. Manchikanti L, Malla Y, Cash KA, Pampati V. Do the gaps in the ligamentum flavum in the cervical spine translate into dural punctures? An analysis of 4,396 fluoroscopic interlaminar epidural injections. Pain Physician 2015; 18:259-266.

12. Kim M, Park KS. Intracranial chronic subdural hematoma presenting with intractable headache after cervical epidural steroid injection. J Korean Neurosurg Soc 2015; 58:144-146.

13. Reitman CA, Watters W 3rd. Subdural hematoma after cervical epidural steroid injection. Spine (Phila Pa 1976) 2002; 27:E174E176.

14. Williams KN, Jackowski A, Evans PJ. Epidural haematoma requiring surgical decompression following repeated cervical epidural steroid injections for chronic pain. Pain 1990; 42:197-199.

15. Xu R, Bydon M, Gokaslan ZL, Wolinsky JP, Witham TF, Bydon A. Epidural steroid injection resulting in epidural hematoma in a patient despite strict adherence to anticoagulation guidelines. $J$ Neurosurg Spine 2009; 11:358-364.

16. Fitzgibbon DR. Chronic pain management: ASA closed claims project. Anesthesiology 2004; 100:98-105.

17. Rathmell JP, Michna E, Fitzgibbon DR, Stephens LS, Posner $\mathrm{KL}$, Domino KB. Injury and liability associated with cervical procedures for chronic pain. Anesthesiology 2011; 114:918-926.

18. Norouze S, Benzon HT, Provenzano DA, Buvanendran A, De Andres J, Deer TR, Rauck R, Huntoon MA. Interventional spine and pain procedures in patients on antiplatelet and anticoagulant medications: Guidelines from the American Society of Regional Anesthesia and Pain Medicine, the European Society of Regional Anaesthesia and Pain Therapy, the American Academy of Pain Medicine, the International Neuromodulation Society, the North American Neuromodulation Society, and the World Institute of Pain. Reg Anesth Pain Med 2015; 40:182-212.

19. Groen RJ, Ponssen $\mathrm{H}$. The spontaneous spinal epidural hematoma. A study of the etiology. J Neurol Sci 1990; 98:121-138.

20. Lim SH, Hong BY, Cho YR, Kim HS, Lee JI, Kim HW, Ko YJ. Relapsed spontaneous spinal epidural hematoma associated with aspirin and clopidogrel. Neurol Sci 2011; 32:687-689.

21. U HS, Wilson CB. Postoperative epidural hematoma as a complication of anterior cervical discectomy. Report of three cases. J Neurosurg 1978; 49:288-291.

22. Horlocker TT, Wedel DJ. Neuraxial block and low-molecular weight-heparin: Balancing perioperative analgesia and thromboprophylaxis. Reg Anesth Pain Med 1998; 23:164-177.

23. Yoo HS, Park SW, Han JH, Chung JY, Yi JW, Kang JM, Lee BJ, Kim DO. Paraplegia caused by an epidural hematoma in a patient with unrecognized chronic idiopathic thrombocytopenic purpura following an epidural steroid injection. Spine 2009; 34:E376-E379.

24. Takahashi K, Koewa F, Tayama H, Satomi A, Akizawa T, Ideura T. A case of acute spontaneous epidural haematoma in a chronic renal failure patient undergoing haemodialysis: Successful outcomes with surgical management. Nephrol Dial Transplant 1999; 14:2499-2501.

25. Yokota S, Hirabayashi Y, Wakata M, Maruyama Y, Mukoyama A, Nomura M, Hamada S, ljichi N, Matsumoto T, Shima M. Mild hemophilia A diagnosed at the onset of acute epidural hematoma after lumbar epidural block. Rinsho Ketsueki 2011; 52:78-83.

26. Kreppel D, Antoniadis G, Seeling W. Spinal hematoma: A literature survey with meta-analysis of 613 patients. Neuorsurg Rev 2003; 26:1-49.

27. Latner AW. Patient's death lands clinician in court for advising cessation of aspirin therapy. MPR, July 12, 2016.

28. Huntoon MA. Anatomy of the cervical intervertebral foramina: Vulnerable arteries and ischemic neurologic injuries after transforaminal epidural injections. Pain 2005; 117:104-111.

29. Rathmell JP, Benzon HT, Dreyfuss P, Huntoon M, Wallace M, Baker R, Riew KD, Rosenquist RW, Aprill C, Rost NS, Buvanendran A, Kreiner DS, Bogduk N, Fourney DR, Fraifeld E, Horn S, Stone J, Vorenkamp K, Lawler G, Summers J, Kloth D, O'Brien D Jr, Tutton S. Safeguards to prevent neurologic complications after epidural steroid injections: Consensus opinions from a multidisciplinary working group and national organizations. Anesthesiology 2015; 122:974-984.

30. Racoosin JA, Seymour SM, Cascio L, Gill R. Serious neurologic events after epidural glucocorticoid injection--the FDA's risk assessment. N Engl J Med 2015; 373:2299-2301.

31. Manchikanti L, Falco FJE. Safeguards to prevent neurologic complications after epidural steroid injections: Analysis of evidence and lack of applicability of controversial policies. Pain Physician 2015; 18:E129-E138.

32. Vandermeulen EP, Van Aken $\mathrm{H}$, Vermylen J. Anticoagulants and spinal-epidural anesthesia. Anesth Analg 1994; 79:1165-1177.

33. Wulf $\mathrm{H}$. Epidural anesthesia and spinal haematoma. Can J Anaesth 1996; 42:1260-1273.

34. Stoll A, Sanchez M. Epidural hematoma after epidural block: Implications for its use in pain management. Surg Neurol 2002; 57:235-240. 